\title{
Borderline Kişilik Bozukluğunun Ergenlik Döneminde Belirlenmesine Dair Bir Değerlendirme
}

DOI: 10.26466/opus. 898571

\author{
Haydeh Faraji* \\ * Dr. Öğr. Üyesi, İstanbul Aydın Üniversitesi, Fen Edebiyat Fakültesi, İstanbul/ Türkiye \\ E-Posta: haydehfaraji@aydin.edut.tr ORCID:
}

Öz

Borderline kişilik bozukluğu; bireyin kimlik duygusu, ilişsileri, duygulanımı, davranışları ve bilişsel örüntüsünde, yaygin ve süreğen bir dengesizliğin hakim olduğu bir bozukluktur. Borderline kişilik bozukluğu yüksek düzeyde komorbiditeye sahip olup; risk alma davranışları, intihar ve kasıtlı kendine zarar vermenin sıklıkla görüldüğü, işlevsellikte düşüşün yaygın ve şiddetli olduğu bir bozukluk olarak yüksek düzeyde kamu maliyeti yaratmaktadır. Tanılamaya yönelik kategorik yaklaşımın kişilik bozukluğu tanısı için 18 yaş sınırı çizmesi ve "kişilik bozukluğu damgasının" önüne geçme kaygısı nedeni ile ergenlik döneminde borderline kişilik bozukluğu tanılaması tartışmalı bir konudur. Ancak bozukluk boyutsal olarak ele alındığında ergenlik döneminde de kendilikte, ilişkilerde, duygularda, davranışlarda ve bilişlerde normatif ergenlerden daha farklı biçimde düzensizlik gösteren ergenlerin varlığıyla karşılaşılmaktadır. Üstelik yoğun, yaygın ve esneklikten yoksun borderline kişilik özelliklerinin varlı$\breve{g}$ l, ergenin erken yetişkinliğe geçerken önemli gelişimsel kilometre taşlarına ulaşma becerisini olumsuz etkileyebilmektedir. Hastalığın hem bireysel hem de kamusal maliyetinin önüne geçmek ve hastalı̆̆ın yıkıcı sonuçlarına önlemek adına erken teşhis önem taşımaktadır. Bu derleme makalesinde ergenlik döneminde borderline kişilik bozukluğu teşhisinin tartışmalı doğası incelenmiştir.

Anahtar Kelimeler: Borderline Kişilik Bozukluğu, Ergenlik, Kasıtlı Kendine Zarar Verme, Risk Alma, Dürtüsellik. 


\title{
Evaluation of Determining Borderline Personality Disorder in Adolescence
}

\begin{abstract}
Borderline personality disorder; It is a disorder dominated by a common and chronic imbalance in the individual's sense of identity, relationships, affect, behaviors and cognitive patterns. Borderline personality disorder has a high level of comorbidity, risk-taking behaviors, suicide and deliberate self-harm is common, and the decline in functionality is common and severe, and creates high public costs. The diagnosis of borderline personality disorder in adolescence is a controversial issue, since the categorical approach to diagnosis sets an age limit of 18 for the diagnosis of personality disorder and prevents the "personality disorder stigma". However, when considered dimensionally, there are adolescents who show irregularities in self, relationships, emotions, behaviors and cognitions in a different way than normative adolescents. Moreover, the presence of severe borderline personality traits can negatively affect the adolescent's ability to reach important developmental milestones as they move into early adulthood. Early diagnosis is important in order to avoid both individual and public costs of the disease and the devastating consequences of the disease. This review article examines the controversial nature of the diagnosis of borderline personality disorder in adolescence.
\end{abstract}

Keywords: Borderline Personaality Disorder, Adolescence, Deliberate Self Harm, Risk Taking, Impulsivity. 


\section{Giriş}

\section{Borderline Kişilik Bozukluğu}

Borderline kişilik bozukluğu (BKB); bireyin kimlik duygusu, ilişkileri, duygulanımı, davranışları ve bilişsel örüntüsünde yaygın ve süreğen bir dengesizliğin hakim olduğu bir bozukluktur. Mesleki, sosyal ilişkilerde işlev bozukluğu da dahil olmak üzere karmaşık psikososyal sorunlara yasal ve finansal sorunlara yol açabilmektedir (Tomko ve ark., 2014). Genel popülasyonda BKB prevalansı nispeten düşükken, \% 0,5 ile \% 3,9 arasında (Lenzenweger, 2008), psikiyatrik bakımda yatan hastaları \% 30-49'u (Chanen ve Kaess, 2012) ve ayaktan tedavi görenlerin \% 15'i BKB tanısı almaktadır (Zimmerman ve Mattia, 1999). Acil servise başvuran intihara meyilli ergenlerde ise sinırda kişilik bozukluğu oranı \% 78'e çıkmaktadır (Guilé ve ark., 2018). Bozukluğun yükü, intihar sonucu ölen hastaların yüksek prevalansıyla da ilişkilidir: BKB hastalarının \% 10'a kadarı intihar nedeniyle ölmektedir ki bu oran genel popülasyonunki tamalanmış intihar oranının neredeyse 50 katıdır (Lieb ve ark., 2004). Ergenlerde yaygınlık ve seyre dair epidemiyolojik veriler sinırlıdır. Konservatif nokta yaygınlık tahminleri \% 0,9 (Johnson ve ark., 2008). Kümülatif yaygınlık oranları, gençlerin \% 1,4'ünün 16 yaşına kadar BKB için tanı kriterlerini karşılayacağını ve 22 yaşında \% 3,2'ye yükseleceğini göstermektedir (Kaess ve ark., 2014).

BKB'nin anksiyete bozuklukları, duygudurum bozuklukları, yeme bozuklukları, alkol/madde kötüye kullanımı ve bağımlılı̆̆ı ve diğer kişilik bozuklukları ile komorbiditesi bulunmaktadır. Bozukluğa en çok anksiyete bozuklukları \%84,8, duygudurum bozuklukları \% 82,7 alkol/ madde kötüye kullanımı \%78,2 eşlik etmektedir (Tomko ve ark., 2014).

Borderline hastalar diğer psikiyatrik bozuklukları olanlara göre daha fazla tedavi kullandığından, daha az eğitim niteliği elde ettiğinden ve daha yüksek işsizlik sorunu yaşadıklarından BKB'nin kamu maliyeti önemli düzeyde yüksektir (Ansel ve ark., 2007; Sasone ve Sasone, 2012). BKB tanısı alan kişilerin öykülerine bakıldığında tanılama öncesi hastaneye yatış oranlarının da oldukça yüksek olduğu görülmektedir (Guile ve Greenfield, 2004). Şiddetli borderline kişilik özelliklerine sahip olmak ergenlerin erken yetişkinliğe geçerken önemli gelişimsel kilometre taşla- 
rına ulaşma becerilerini olumsuz etkileyebilmektedir (Winograd ve ark., 2008). Bu gözlemler birlikte ele alındığında, borderline psikopatolojinin zaman içinde yerleşmesini önlemek için erken tanılamanın ve müdahalenin önemli olduğunu kuvvetle göstermektedir (Beauchaine ve ark., 2008).

Takip çalışmaları remisyonun yaygın olduğunu göstermektedir - 6 yıl sonra\% 74; 10 yıl sonra\% 88 (Zanarini ve ark., 2003; 2006). Yüksek remisyon oranı BKB'nin kronik, aralıksız bir durum olmayabileceği fikrini gündeme getirse de esas durum, BKB'yi meydana getiren iki belirti kümesinden öfke ve terk edilme duyguları ile karakterize edilenin sabit ya da kalıcı olma eğilimi göstermesi, buna karşın kendine zarar verme ve intihar girişimleri ile karakterize olan belirti kümesin kararsız ya da daha az kalıcı bir doğaya sahip olmasıdır. Çoğu durumda remisyon bu ikinci küme semptomlarda azalmayı ifade etmekte, hastalığın tamamen ortadan kalkması anlamına gelmemektedir (Gunderson, 2003). Bununla birlikte ergenlik döneminde tanı konulduğunda remisyon daha yüksek olmaktadır (Biskin ve ark., 2011).

\section{Ergenlikte BKB Teşhisi}

Kişilik bozukluklarının kökenlerinin çocukluk ve ergenlik döneminde olduğu konusunda uzun süredir devam eden genel kabul görmesine rağmen, BKB'yi 18 yaşından önce teşhis etmek tartışmalı bir konudur (Chanen ve McCutcheon, 2008). Dünyanın farklı noktalarında ruhsağlığ hizmeti veren pek çok klinisyen tanılama ile ilgili 4 temel başlık nedeniyle BKB teşhisi koymakta tereddüt yaşamaktadır. Bunların ilki BKB tanısının ergenlik dönemi için geçerli olmayıp 18 yaş üstü için kullanılabilen bir tanı kategorisi olmasıdır. İkincisi, duygusal dengesizlik ya da rahatsız edici öz görüntü gibi BKB'nin tipik özelliklerinin ergenler arasında normatif olmasıdır. Üçüncüsü, ergenlik dönemindeki bir bireyin kişiliğinin henüz gelişim halinde olması nedeniyle değişmekte oluşudur. Dördüncü ve muhtemelen en önemlisi klinisyenlerin hastalarını BKB tanısının getireceği damgalayıcı ve kötümser tutumlardan korumak istemeleridir (Chanen ve ark., 2008).

Ergenlerde BKB teşhisinin kullanımına karşı argümanlar, ergen kişiliğinin dinamik ve gelişen doğasına dayanmaktadır. Ergenler, kişilerarası 
maruz kalma, yansıtma ve devam eden nörobilişsel değişikliklerin bir sonucu olarak sürekli öğrenip geliştiklerinden, ergen kişiliği doğası gereği dinamiktir ve bu dinamiklik yapılanma haline gelmiş olan bir kişilik bozukluğu tanısını dışlayan bir nitelik olarak görülmektedir. Oysa ki başka bir cepheden değerlendirildiğinde bu dinamik yapı, henüz oluşmakta ve gelişmekte olan kişilik örüntüsünde yolunda gitmeyen oluşumların çözümlenmesi için önemli bir avantaj sunmaktadır. Boylamsal çalışmalar sonucu BKB tanı kriterlerini karşıladıkları tespit edilen ancak yetişkinliklerinde kriterlerini artık karşılamayan bireylerde çok sayıda borderline semptomun varlığının devam ettiği görülmüştür. Kalıcılık gösteren semptomlar; bakım verme ve alma deneyimi, bağımlılık, mazoşizm ve depresyonla ilgili çelişkili duygularından oluşmaktadır. Bu durum, BKB'nin ergenlik dönemi formunun, yetişkin ylllarda mutlaka BKB'ye yol açmayacağını ortaya koysa da, Kernberg'in (1990) savunduğu gibi, orta ila şiddetli borderline psikopatolojisi olan ergenler, bu psikopatolojiyi nadiren geride birakabilmektedir.

BKB yapısal ve sabit bir model olarak düşünülmeksizin, kişilik “örüntüsüne dair" boyutlar olarak ele alınması ve bu boyutların katılık düzeyi ve farklı durum ve koşullara adaptasyon gücü üzerinden değerlendirilerek ergenlerde boderline kişilik bozukluğu düzeyindeki durumların teşhis edilmesi sözü geçen özellik ve örüntülerin kemikleşerek değişmesi oldukça güç bir yapı haline gelmesinin önüne geçecektir (Greenfield ve ark., 2015).

DSM kriterleri (APA, 2013) harfiyen takip edilirse, BKB sadece yetişkinlerde teşhis edilebilir. Ancak yetişkin olma durumundan ve "kişilik"ten bireyin 18. yaş gününde ortaya çıkan bir fenomen olarak söz ettiğimizde bu kişilerin 18. yaş günlerinin bir gün öncesi ve birgün sonrasındaki farkın ne olduğu sorusu ortaya çıkmaktadır. Bu doğrultuda, yetişkinlere göre daha düşük bir öngörü gücü olduğunun kabul edilmesi ve değişmesi güç bir bozukluktan öte "bazı boyutların yaygın, yoğun ve esneklikten yoksun hale geldiği bir örüntü" olarak kabul edilmesi koşuluyla bu tanının ergenlerde yapılabileceğini düşünülmektedir (Bondurant ve ark., 2004).

Mevcut taksonomilerin eksikliklerine dair farkındalık, bozukluğun boyutsal bir kavramsallaştırılmasına doğru bir eğilim oluşturmuştur. 
Boyutsal yaklaşım BKB'ye dair duygusal, davranışsal, bilişsel, kişilerarası düzensizlik ve kendilik düzensizliği boyutlarını içermektedir.

\section{Borderline Kişilik Bozukluğu Boyutları}

Duygusal Değişkenlik: BKB'de duygulanım olumsuz, yoğun ve değişkendir. Hemen hemen her zaman bir kriz durumda olduğu görülen borderline hastalarda duygulanım dalgalanmalarıyla sıklıkla karşılaşılmaktadır. Öfke, duygulanımsal oynaklığın kilit faktörü olarak karşımıza çıkmakta ve zaman zaman anlamlı ötekilerin, özellikle de temel bakım verenlerin (genellikle anne-baba), değersizleştirilmesi yahut değersizleştirmenin yansıtılması ile birlikte görülebilmektedir. BKB'de duygulanım tipik olarak negatif duygular olan öfke, sinirlilik, kayg1, depresyon, disfori arasında dalgalanmalar ve geçişler göstermektedir. Yoğun öfke; ihtiyaç duyulan nesneyle kontağı sürdürmek, onu kontrol edebilmek ve nesne olan ilişkiye bağlı olarak kendilik duygusunu sürdürebilmek adına başvurulan temel yoldur. Bu noktada borderline hastada karşılaştığımız depresif duygulanımın, daha az ayırt ettiricidir. Borderline hastaların içsel boşluk hissiyle ilişkili olan disforik duygulanımları, BKB'de karşılaştığımız çökkünlüğü majör depresyondan ayırt edebilmemizi sağlamaktadır (Faraji, 2020).

Borderline ergenler bir an çok mutlu görünürken, bir an sonra öfkeli, ağlamaklı ya da heyecanlı hale gelebilmekte ve hizlı bir şekilde sakinleşmiş bir hale bürünebilmektedirler. Dengesiz ruh hali, duygusal aşır1lıkları kontrol etmede güçlükle birlikte, BKB'li bireyler için tanımlayıcı bir sorundur. Kararsız ruh halleri, BKB'si olmayan ergenlerde de karş1mıza çıkabilmektedir. Ancak BKB söz konusu olduğunda, duygusal iniş çıkışlar genellikle hayal kırıklığı ve kişiler arası çatışmayla tetiklenir ve ruh halinin aşırılıklarıyla yaygın ve yoğun bir şekilde karşılaşırız. BKB'li ergenlerin ruh hali değişimlerini tipik ergen ruh hali değişimlerinden ayıran bu yoğunluktur. BKB'li ergenler, duyguları daha hizlı ve yoğun hissettiklerini ve BKB'si olmayan arkadaşlarına göre sakinleşmelerinin daha uzun sürdüğünü ifade etmektedirler. Ayrıca iyi bir ruh halindeyken neredeyse her şeyi yapabileceklerine, ancak kötü bir ruh halindeyken neredeyse hiçbir şey elde edemeyeceklerine inanma eğilimi göster- 
mek gibi iki uçlu "ya hep ya hiç tarzı" düşünme eğilimi sergilerler (Aguirre, 2014).

Davranışsal Değişkenlik: Borderline hastalar genellikle duygularını kontrol etmekte güçlük çekmekte, borderline hastaların bedenlerinin kontrolden çıktığından söz ettikleri konuşmalarla sıklıkla karşılaşılmaktadır. Borderline hastaların hem doğalarının bir gereği hem de yetiştirilme şartlarının etkisiyle, dürtüsellik, özellikle agresif dürtüsellik, BKB'nin önde gelen bileşenlerinden biri olarak kabul edilmektedir (New ve Siever, 2002; White ve ark., 2003).

Madde kötüye kullanımı borderline hastalar arasında yaygındır. Borderline hasta çoğunlukla gelişigüzel cinsel yaşantılar ve intihar girişimleriyle belirli kendine zarar verici ve saldırgan dürtüsellik dönemleri yaşamaya da eğilimlidir. Bu dürtüsel davranışlar, ana nesnenin kaybına atfedilebilen panik ve dezorganizasyon duygusundan kaçınmak ve kaybolan nesne ya da yeni kalıcı nesnelerle temas kurmaya çalışmak için ikili amaca hizmet edebilmektedir (Fein ve ark., 2018).

Madde kullanımı hem kaygıyı giderir hem de geçici bir nesne olarak hizmet eder, bununla birlikte, maddenin etkileri nesne bağlantılarının yolunu açabilmektedir (örneğin dürtüsel cinsel karşılaşmalar). Bununla birlikte terk eden nesneye karşı açı̆̆a çıkan öfkenin içe atılıp kötü kendilik temsili haline gelmesi nedeniyle kendine zarar verici davranışlar ve intihar girişimleri ötekilerle gerçek yaşamda ya da fantezideki ilişkilerin ardından ya da eş zamanlı şekilde ortaya çıkmaktadır. Bu tarz kendine zarar verici ve öz yıkıcı eğilimlerle istismar geçmişleri olan borderline hastalarda fazla karşılaşılmaktadır (Brodsky ve ark., 1997; Sansone ve ark., 2002).

Öfke, kaygı ve hayal kırıklığı gibi olumsuz nitelikli baş edilemeyen duygular kendine zarar verme davranışının ortaya çıkışından önce gelir (Klonsky ve Muehlenkamp, 2007). Morbid bir kendi kendine yardım biçimi olarak kendine zarar verme davranışı, sık sık kaygılanmak, kaotik düşünceler ve hızla değişen duygular gibi rahatsız edici semptomlardan hızlı, ancak geçici bir rahatlama sağlar. Kaygı, depresif belirtiler ve öfkenin şiddeti kendine zarar verme davranışının öncülleri olarak kabul edilmektedir (Evren ve ark., 2012). 
Kayıp bir psikolojik güç unsuru olarak arabuluculuğun yokluğu, kişiliğin yokluğu ve kendiliğin bedensel deneyimlerle sınırlı olması duyumlarıyla kendini gösteren, kronik boşluk duygularına neden olmaktadır. Birçok çalışmacı, borderline hastaların kendilerine zarar verici davranışlarının bir intihar girişimi olmadığını (örneğin, kesme ve kendiliğinden kaynaklanan yanıklar), belirli bir rahatlama ve "akıntı" deneyimi veren duygusal düzenleme stratejilerine benzediklerini belirtmektedir (Monti ve D'Agostino, 2016).

Borderline hastalarda; duyguların bedensel ortam yoluyla düzenlenmesi, her birey için temsil ettiklerine göre farklı biçimler alabilmektedir: ruhsal ağrıya fiziksel form verilmesi; kendini cezalandırma ya da disforisini düzenleme; bir iz bırakarak belirli olayları hatırlamak (bir yara izi); ya da daha aktif hissetme (pasif olarak deneyimlemek yerine birinin deneyimlerinin temsilcisi olmak) söz konusudur (Monte ve Engelebert, 2018).

Fiziksel acı, aracilık edilemeyen psişik bir acının alternatifi olarak kullanılmaktadır. Borderline hastaların dövmelere olan sık ilgisi bu hipotezler ışığında da yorumlanabilmektedir. Bedeni oyuna getirmek, beden ile benlik arasındaki belirli bir ilişki biçimini belirleyen sıkıntının üstesinden gelmenin bir yolu olan paradoksal bir çözüm arayışıdır (Faraji, 2020).

Tüm BKB davranışlarının en endişe verici olanı intihar düşünceleri ve girişimleridir. BKB'li ergenler genellikle kendilerine zarar verirler (sıklıkla kendilerini kesmek şeklinde) ve bunu yapmalarının en tipik nedeni, yoğun duyguları düzenlemeye çalışmalarıdır. Diğer yaralanma biçimleri arasında yanma, kesme, delme, kafaya ve duvara vurma yer alır (Evren ve ark., 2012).

Dürtüsellik başka bir davranış değişkenliği sorunudur. BKB'li ergenler adeta "düşünmeden hareket ediyor" görünürler. Dürtüsel davranışlar genellikle güçlü duygular bağlamında gerçekleşir ve aniden okulu bırakmayı, dikkatsizce araç kullanmayı, korunmasız cinsel ilişkilere girmeyi ve alkol/madde kötüye kullanımını içermektedir (Aguirre, 2014). 


\section{Risk Alma ve Kendine Zarar Verme}

Ergenlik döneminde davranışsal değişkenliğin ciddi sonuçlara yol açabilen bir alt türü olarak risk alma ve kendine zarar verme davranışlarından ayrıca söz etmek gereklidir. Risk alma davranışları ve kendine zarar verme davranışları ergenlik döneminde sıklıkla ortaya çıan olgulardır (Kaess ve ark., 2014a, b). "Kasitlı kendine zarar verme" (KKZV) terimi, intihar niyeti olsun olmasın bir dizi farklı kendine zarar veren davranışı içeren, kişinin kendi vücut dokusunu kasıtlı olarak doğrudan tahrip etme eylemi olarak tanımlanmaktadır (Brunner ve ark., 2014). Risk alma davranışları, ergenlerin fiziksel iyilik halini ve psikososyal işlevselliğini etkileyebilecek davranışlar olarak tanımlanır ve madde kullanımı, aşırı medya kullanımı ve karışıklık dahil olmak üzere çok çeşitli davranışları içerir (Leather, 2009).

Risk alma davranışının genel ergen popülasyonunda "normatif" bir davranış kompleksi olmasının yanı sıra bir dizi psikolojik problemle ilişkili olduğu bilinmektedir (Carli ve ark., 2014). Risk alma davranışı, ergenlik döneminde psikiyatrik bozukluklar geliştirmeye yönelik savunmasızlı̆̆ın bir işareti olabilir (King ve ark., 2001). Kendine zarar verme davranışı genellikle ergenlik döneminde genç yetişkinliğe doğru geçişte önemli ölçüde azalan geçici bir fenomen olarak karşımıza çımaktadır (Moran ve ark., 2012).

Kendine zarar verme davranışı diğer risk alma davranışlarıyla ilişkilidir (Moran ve ark., 2015). Duygusal ve davranışsal düzensizliğin akut belirtileri, başta kendine zarar verme davranışı ve risk alma davranışları, ergenlikte BKB'nin tanısal temel özellikleridir (Kaess ve ark., 2014a). KKZV'nin varlığı ve daha yüksek sıklığı, daha fazla BKB semptomunun onaylanmasıyla ilişkilidir (Cerutti ve ark., 2011). KKZV BKB'deki duygusal düzensizlik ve kişilerarası düzensizlikle yüksek düzeyde ilişkili bulunmuştur (Vega ve ark., 2017). BKB'li ergenler daha erken yaşta KKZV davranışları sergiler ve BKB'si olmayan ergenlere kıyasla daha uzun bir KKZV öyküsü bildirirler (Groschwitz ve ark., 2015).

Bilişsel Değişkenlik: Borderline hastalar gerçeklikle ilişkiyi sürdürmekte güçlük çektiklerinden yapılandırılmamış ya da stresli durumlarda, bilişsel bozuklukları özellikle belirginleşmektedir. Bu geçici bilişsel bozuk- 
luklar; disossiasyon, paranoya ve durumsal şekilde diğer yarı psikotik deneyimleri de içermektedir. Bu durumdaki "stres unsuru" tipik olarak, kaybın kaçınılmaz ve geri döndürülemez olduğu hissedildiği önemli bir nesneyle temas kaybı olmaktadır. Diğer geçici yarı-psikotik deneyim türlerinden olan düşünce eklemesi, düşünce kontrolü, görsel ve işitsel hallüsinasyonlar vb. BKB ile ilişkilidir. Ancak bu inançların ve duyusal deneyimlerin gerçeklikle uyumluluğu keskin psikozdan daha yüksek düzeydedir. Bu geçmiş psikotik deneyimlerin ayrıca, tekrarlanan hastaneye yatışları tetiklediği belirlenmiştir. Bu nedenle psikotik tarz bilişsel deneyimler borderline hastada ruhsal işleyişteki zayıflık ve kırılganlığın göstergesi olarak kabul edilmektedir (Faraji, 2020).

Borderline hastaların özellikle de ergenlerin bilişsel değişkenliğine sebep olan faktörlerden biri sevilmedikleri, kötü, zehirleyici, iğrenç ve hatta "şeytan" oldukları gibi yaygın irrasyonel inançlarıdır (Aguirre, 2014). Bu inançlar BKB’li ergen üzerinde önemli ölçüde baskı yaratmakta ve düzenlenemeyen olumsuz duygulanımlara yol açabilmekte, kendilerine zarar vermelerine ve hatta intihar girişimlerine neden olabilmektedir.

Kişilerarası Değişkenlik: Aynı anda hem bağlılık hem düşmanlık hisseden bu hasta grubu düzensiz kişilerarası ilişki örüntülerine sahiptirler. Kişilerarası ilişkilerde dengesizlikle sıklıkla karşılaşılması ve dengesizliğin borderline hastaların günlük yaşamında oldukça yaygın bir görünüm sergilemesi, bu özelliği BKB tanılamasında temel bir özellik haline getirmiştir (Kahraman, 2018).

Yalnızlığa karşı toleranslarının oldukça düşük olduğu, zorlantılı bir biçimde sosyalleşmeye çalıştıkları, sıklıkla can sıkıntısı ve içsel boşluk duygusundan yakındıkları gözlenmektedir. Şiddetli duygusal dalgalanmalar ve dramatik davranışlar sergilemekte, uç noktalara varan yargilarda bulunabilmektedirler. Diğer insanlara yönelik duygu ve tutumları kısa süre içinde dikkat çekici düzeyde ve açıklanamaz biçimde değişebilmektedir. Duygu dalganmaları tutkulu bir idealizasyondan, hor görme ve öfkeye doğru hızlı ve kesin şekilde, bir uçtan öteki uca savrulmalarla açığa çıkmaktadır. Bu kişilerde sıklıkla aşırı para harcama, kumar oynama, uygunsuz cinsellik ve yeme atakları gibi öngörülmesi güç şekilde aniden ortaya çıkan ve kişinin zarar görmesiyle sonuçlanma ihti- 
mali yüksek olan davranışlarla karşılaşılmaktadır. Tümgüçlü idealizasyon ve devalüasyon savunma mekanizmaları arasındaki süreğen kararsızlık nedeniyle, genellikle küçük sosyal ağların varlığı ve uzun süreli ilişkilerin eksikliği ortaya çıkmaktadır (Liebke ve ark. 2017).

Borderline hastalar ilişkilerini tutarlı ve kararlı bir biçimde sürdürmekte, sıcak ve empatik olmakta güçlük çekmektedirler. Genellikle "fırtınalı" ve kalıcllıktan uzak ilişkiler kurmaktadırlar. Borderline kişide kendi ve ötekileri bütüncül bir şekilde tasarımlandıramama, kimlik karmaşası, sıklıkla can sıkıntısı şeklinde kendini gösteren süreğen boşluk duygusu, yalnızlık ve terk konularına aşırı hassasiyet gözlenmektedir. Kendilik algısı ötekilere bağlı olduğu, nesne sürekliliği olmadığı için yalnızlığa tahammül güçleşebilmekte ve kişi "yapışkan" bir ilişki tarzı benimseyebilmektedir. Grandiözite sonucu kendilerini diğerlerinden "farklı" olarak algılamaya eğilimli olan bu kişiler, hayal kırıklığı ve eleştiriye karşı oldukça duyarlı olabilmektedir (Atak, 2012).

Borderline hastaların kişilerarası ilişkilerinde bozulma yaratan bir diğer nokta bu kişilerin etraflarındaki bireyleri düşmancil değerlendirme eğilimleridir. Borderline hastalar son derece yüksek bir reddedilme duyarlılığından muzdariptir, reddedilmeyi kaygıyla beklerler ve algılanan red yaşantılarına şiddetli biçimde tepki gösterme eğilimindedirler (Hepp ve ark. 2018).

BKB'nin temel özelliklerinden biri olan reddedilme korkusu, bir çeşit terk edilme yaşantısı olarak ele alınmaktadır. Reddedilme duyarlılı̆̆ı; reddedilmenin kaygılı beklentisi (beklenti anksiyetesi), hızlıca algılanması ve reddedilmeye karşı tepki düzeyinin artış gösterilmesi olarak tanımlanmaktadır. Reddedilme algısı, şiddetli bir gerilime neden olmaktadır. Ciddi düzeyde ve uzun süreli bir şekilde, yaşamlarındaki önemli ötekiler tarafından reddedilme deneyimleri, borderline hastada maladaptif bir korunma yolu olarak reddedilmeye karşı savunucu beklentilerin oluşmasına neden olabilmektedir. Bu eğilim, reddedilmeye dair öngörünün yine uygunsuz bir biçimde ortaya çıktığı deneyimler tarafından tetiklenebilmektedir. Bunun sonucunda, sosyal etkileşimdeki en küçük ipuçları bile reddedilme olarak yorumlanabilmektedir. Bu uygunsuz yorumlamalar, diğerlerini ya da kendini incinmiş hissetmeye ya da kendini suçlayarak kızgın hissetmeye neden olurken geri çekilme ya da saldırganlık gibi işlevsel olmayan davranışları beraberinde getirebilmekte- 
dir. Üstelik tüm bu algilama ve yorumlama biçimleri adeta kendini gerçekleştiren kehanet haline gelerek, gerçek reddedici kişilerarası deneyimlere yol açabilmektedir. Reddedilme duyarlılığı yüksek olan borderline hasta reddedilme riskini düşüreceğine inandığında; cinsel eylemde uygun sinırlar koyamama ya da koyduğu sinırları bunları uygulamada zorluk yaşama gibi davranışlar göstererek mağdur olma riskini yükseltmektedir (Faraji, 2020).

Hastaneye yatırılan BKB'li ergenlere bakıldığında, genellikle bir romantik ilişki bitiminde ya da sevilen bir kişi ile gerçek ya da algılanan ayrılık tedavi görmek için yatırıldıkları görülür. Bu tür ayrılıklar genellikle çaresizliğe yol açar ve tipik olarak kendi kendini yok etme gücünde bir artış görürüz. Bazen intiharı düşünmüş ya da intihara teşebbüs etmiş olacaklardır. Ancak sevilen kişinin BKB'li ergenden ayrılmaya niyeti olmasa bile böyle bir umutsuzluk yaşanabilir. Sevdiklerinin bir randevuya geç kalması ya da bir telefon görüşmesine cevap vermemesiyle bile tetiklenebilen reddedilme düşüncesi, umutsuzluk duymaya ve yıkıc1 davranışlara yol açabilir (Aguirre, 2014).

Kendilikte Değişkenlik: İstikrarlı bir kendilik duygusunu sürdürmekte güçlük BKB'nin yaygın bir özelliğidir. Varoluşumuzu şimdiki andan ayıran "sınır" bu kişiler için yoktur yahut muğlak durumdadır. Borderline hastaların "şimdiki an" ile sınırlı varlıkları, duygusal dengesizliklerini ve ilişkisel tutarsızlıklarını körüklemektedir. Borderline hastanın kendini deneyimlerinden uzaklaştırması zor olmakta; birey, deneyimleri ve kendisi arasında tatmin edici bir mesafe ayarı yapamamaktadır. Borderline hastanın süreçleri, yaşantıladığı an ile belirleme eğilimi bulunur, şimdiki ana tamamen dalmış durumdadır. Bu kişiler için birey, şimdi ve burada yaşantıladığı her ne ise onunla sınırlıdır. Şimdiki an ile kendiliği ayıran hiçbir sınır yoktur, bu ikisi birbirine nufüz etmiş ve iç içe geçmiş durumdadır (Englebert, 2017).

Benlik, deneyimlenen kendilik ve gözleyen kendilikte bir fragmantasyon söz konusudur. Benliğin bu geçici parçalanması, uzun süreli kişilerarası ilişkilerin bir parçası olan belirsizliğe dair özgün bir hoşgörüsüzlük biçimi ile uzun süreli ilişkilerin beraberinde gelen bağlllık, sorumluluk ve suçluluk duygularının reddedilmesine neden olmaktadır. 
Ergenlerin benlik hislerinin olmadığını, kendilerini boş hissettiklerini ve kim olduklarını ya da ne istediklerini bilmediklerini söylemeleri alışılmadık bir durum değildir. Ergenler de ihtiyaçlarını, duygularını, sevdiklerini ve hoşlanmadıklarını başkalarına ifade etmekte sık sık güçlük çekerler, etrafındakilerin fikirlerinden ve eylemlerinden kolayca etkilenebilirler. Dış görünüşlerle çok ilgilenme eğilimindedirler ve sıklıkla kendilerini ve durumlarını başkalarınınkilerle karşılaştırarak kendileri hakkında bir değerlendirmeye vardıklarından sürekliliğe sahip olan stabil bir kendilik algısından söz etmek güçtür (Faraji ve Tezcan, 2021). Tipik bir şekilde ben ve öteki arasındaki sınırın muğlaklığı ile karakterize olan kimlik karmaşası borderline hastaların yaşadığı kişiler arası ilişkiler sorunlarının pek çoğunu açıklar görünmektedir. Bu sınır muğlaklı$\breve{g}_{1}$, borderline hastaların çalkantılı ilişkiler yaşamasına neden olan, kendilik ve öteki hakkında aşırı iyi ve aşırı kötü şeklinde ortaya çıkabilen ikiuçlu düşünce biçiminde de kendini göstermektedir (Faraji, 2020).

Normatif ergenlere benzer ancak daha yoğun bir biçimde, BKB'li ergenler kim olduklarına dair istikrarlı bir duyguyu tanımlamada zorlanırlar. Değerleri, ahlakları ve kimlikleri akışkan ve değişken görünür ve çoğu zaman, benlik hisleri o anda arkadaş grubuyla özdeşleşmeleriyle belirlenir. Pek çoğunun ebeveyni çocuğunu tanıdığını düşünürken şaşırtıcı ve zorlayıcı durumlarla (örn; intihar girişimi) karşı karşıya kalır. Ebeveynlerin bir kısmı ise çocuklarının her zaman onlar için "bir kapalı kutu" olduğunu, hiçbir zaman rahatlıkla çocuklarının sonraki adımını ön göremediklerini belirtmektedir. Birden fazla çocuğu olan ebeveynler genellikle ergenlik çağındaki BKB'li çocuklarını BKB'si olmayan diğer ergenlik çağındaki çocuklarıyla karşılaştırdıklarında, BKB'si olmayan çocukları genellikle daha öngörülebilir ve duygusal olarak stabilken, BKB'li çocuklarının daha dürtüsel ve yatıştırılması zor olduğunu belirtmektedir (Aguirre, 2014).

\section{BKB’li Ergenler ve Tipik Ergenler Arasındaki Davranışsal Farklılıklar}

Tipik ergenler gibi, BKB'li ergenler de içki içebilir, dikkatsizce araba kullanabilir, uyuş̧turucu kullanabilir ve ebeveynlerine meydan okuyabilir. Bununla birlikte, BKB'li ergenler, başta öfke olmak üzere yoğun duygular, boşluk, kendinden nefret etme ve terk edilme korkularıyla başa çı- 
manın bir yolu olarak sıklıkla uyuşturucu kullanır, kendine zarar verir ve ebeveynlerine karşı öfke duyar. BKB'li ergenler, BKB'si olmayan ergenlerin yaşadığı normal ergen gelişiminde aynı zorluklardan ve değişikliklerden geçse de, davranışın anlamını ya da amacını tanımak kritiktir (Aguirre, 2014).

Hem BKB'li hem de normal ergen zaman zaman karamsarlığa kapılabilir, ebeveynlerinin isteklerine meydan okuyan dürtüsel tavırlar benimseyerek alkol/madde kullanımında ve cinsel davranışlarda bulunabilir. Her iki ergen de benzer davranış ve tutumları sergilerken birini BKB tanı katerosine dahil eden bu tutum ve davranışların gördüğü işlevdir. Normatif ergen bu davranışları keşif amaçlı ya da iyi hissetmek adına yaparken BKB'li ergenin amacı genellikle başaçıkamadığı duygularını düzenlemek ve kontrol etmek çabası olmaktadır (Aguirre, 2014).

\section{Ergen Borderline Kişilik Bozukluğunda Psikoterapi}

Ergenlikte BKB'nin hem teşhis edilmesini hem de tedavi edilmesini destekleyen kantlar gün geçtikçe artmaktadır. BKB, yetişkinlikte olduğu kadar ergenlik döneminde de güvenilir ve geçerli bulunmuştur (Chanen ve ark., 2008; Miller ve ark., 2008). BKB ergenlik döneminde yetişkinliğe göre benzer bir istikrar gösterir (Chanen ve ark., 2004). Bozukluğun genç ve erişkin formlarına yönelik tedavilerde bir farklılık olmamakla birlikte bozukluğa özgü tedavide erken müdahale hastalığın seyri ve şiddeti açısından önemli olduğu belirtilmektedir (Chanen ve ark., 2013).

Bilişsel davranışçı terapi, şema terapi, duygusal öngörülebilirlik ve problem çözme için sistem eğitimi, zihinselleştirme temelli tedavi, aktarım odaklı terapi, bilişsel analitik terapi, aile terapisi, kişilerarası psikoterapi, destekleyici psikoterapi günümüzde hem ergen hem erişkin BKB psikoterapisinde kullanılan psikoterapi yöntemlerinden başta gelenleridir.

Bilişsel Davranışçı Terapi: Bilişsel davranışçı terapi (BDT) nasıl hissettiğimizde ve ne yaptığımızda düşünmenin merkezi rolünü vurgulayan bir psikoterapi şeklidir. BDT, psikoterapilerin "en hızlısı" olarak kabul edilir ve terapistler genellikle ortalama on altı seans önermektedir. Yararsız ya da irrasyonel düşünme ve tepki kalıplarını belirlemeyi, tanımayı ve ar- 
dından hastanın bu kalıpları daha pratik ya da yararlı yanıtlarla değiştirmesine yardımcı olmayı amaçlamaktadır. Duygu ve davranışın değişmesi için genellikle düşüncenin değiştirilmesi yolu benimsense de kimi zaman doğrudan davranışa yönelik müdahalelerle duygu ve düşüncenin değişimi sonucuna ulaşılabilmektedir (Türkçapar, 2018).

Şema Terapi: Şema Terapi, terapötik ilişki, duygulanım ve duygudurum durumlarına, yaşam boyu başa çıkma tarzlarına (örneğin, kaçınma ve aşırı telafi), yerleşik ana temalara (ör. Uyumsuz şemalar) daha fazla vurgu yaparak BDT ilkelerini kişilik bozukluklarının tedavisine genişletmeyi amaçlamaktadır. Belirli temel çocukluk ihtiyaçlarının karşılanmamasına karşı gelişen bilişsel şemaların zaman içinde uyumsuz hale geldiği ve kişinin işlevselliğini bozduğu üzerine odaklanılır. Danışanın hayatının merkezindeki şemalar tespit edilir, bu şemaların hayatındaki olumsuz etkileri ortaya konulur, danışanın şemaya ait duygularla temas etmesi sağlanır, işlev bozucu başa çıkma tepkileri ve modları tespit edilir. Bu doğrultuda erken dönem acı ve öfke yaşantılarının kabul edilmesi ile uyumsuz düşünceler ve davranış kalıplarının değiştirilmesine yönelik çalışılır (Rafaeli ve ark., 2013).

Duygusal Öngörülebilirlik ve Problem Çözme için Sistem Eğitimi: Duygusal Öngörülebilirlik ve Problem Çözme için Sistem Eğitimi bir sistem yaklaşımına dayanmaktadır. Bu modelde $\mathrm{BKB}$, bir duygu ve davranış düzenleme bozukluğu olarak anlaşılmaktadır. Amaç, BKB'li kişiye, onları tedavi eden diğer profesyonellere ve yakın arkadaşlara ve aileye, bozukluk ve onu yönetmek için kullanılan beceriler hakkında net bir şekilde iletişim kurmaları için ortak bir dil sağlamaktır. Bu, "bölünmeyi" (kişinin etrafındaki diğerlerini taraf tutmaya ya da "iyi" ya da "kötü" olmaya çalışarak iç çatışmaları dişsallaştırdığı ilkel bir savunma mekanizmasi) önlemeye yardımcı olur (Blum ve ark., 2008).

Zihinselleştirme Temelli Tedavi: Bateman ve Fonagy (1999, 2013) tarafından geliştirilen ZTT, bağlanma teorisine dayalı bir psikodinamik psikoterapötik programdır. Bu modeldeki "zihinselleştirme", kişinin kendi düşüncelerini ve duygularını etrafımızdakilerden ayırt etme ve ayırma yeteneği anlamına gelir. Düzensiz bağlanmanın zihinselleştirme kapasi- 
tesinde bir başarısızlığı teşvik ettiğini varsayar. Bireysel psikoterapi ile grup psikoterapisinden oluşur. Duygusal açıdan zorlayıcı durumlarda hastanın kendisinin ve başkalarının duygularını doğru bir şekilde ifade etme kapasitesini geliştirmeyi amaçlar. ZTT'nin temel amac1, etki düzenlemesini ve davranış kontrolünü iyileştirmektir. Hastaların yaşam hedeflerine ulaşmalarına ve daha samimi ve tatmin edici ilişkiler geliştirmelerine olanak tanır.

Diğer psikodinamik yaklaşımlardan farklı olarak, odak noktası aktarım ya da geçmiş ilişkiler ya da biyografik içgörü geliştirmek değil, amaç mentalizayson kapasitesini geri kazanmaktır. Terapistler, grubun üyeleri arasında ve danışanlar ile terapistler arasında güvenli bir bağlanma bağ geliştirmeye çalışırlar. Bu güvenli bağlanma, kişinin zihnini ve başkalarının zihnini keşfedebileceği bir ilişki bağlamı sağlar.

Aktarım Odaklı Terapi: Aktarım Odaklı Psikoterapi (AOP) bir psikodinamik yaklaşım türüdür. AOP, BKB'nin psikolojik organizasyonunda, benlik ve diğerleri hakkındaki düşüncelerin, duyguların ve deneyimlerin iyi ya da kötü, siyah ya da beyaz, ya hep ya hiç olarak ikiye bölündüğü bir yapının varlığını savunur. AOP'ye göre bu bölünme kaotik kişiler arası ilişkilere, dürtüsel kendine zarar verici davranışlara ve BKB'nin diğer semptomlarına yol açmaktadır. Haftada iki kez bireysel psikoterapi seanslarından oluşan tedavi aktarıma odaklanılırr, çünkü hastaların aktarımda baskın nesne ilişkileri ikiliğini yaşadıklarına inanılmaktadır (Clarkin ve ark, 2007).

Bilişsel Analitik Terapi: Ergenlerde, Bilişsel Analitik Terapi (BAT)16 ila 24 seans süren nispeten kısa bir tedavidir. BAT çeşitli kaynaklardan teori ve pratiğin bir entegrasyonudur. Bilişsel analitik terapinin ana kaynaklar bir yandan bilişsel psikoloji ve bilişsel psikoterapi, diğer yandan daha bilişsel bir dilde yeniden ifade edilen psikanalitik nesne ilişkileri teorisidir. Yöntemdeki vurgu, hastanın problemlerinin yeniden formüle edilmesi üzerinedir ortaya çıkan tarifler, içinde bir dizi terapötik yöntemin uygulanabileceği bir "yapı iskelesi" olarak kullanılır. Bilişsel davranışsal yöntemler ve aktarımın kullanımı, bu tanımların hem terapist hem de hasta tarafından anlama ve değişim araçları olarak kullanılmasıyla birleştirilir (Ryle ve Low, 1993) 
Aile Terapisi: Aile terapisi, bir ailenin birden fazla üyesinin terapiye dahil edildiği bir psikoterapi türüdür. Uzun yıllardır ergen terapisinin kritik bir bileşeni olmuştur. Temel teori, bireylerin davranışlarının diğer aile üyelerinin onlarla etkileşime girme biçiminden etkilenmesi ve sürdürülmesidir. Aile terapisinin iki ana hedefi vardır: Hem aileyi BKB konusunda eğitmeli hem de aileyi tedavi etmelidir. Bu hedeflerin her ikisi de, ergenin anlaşıldığını hissetmesine yardımcı olur. Eğitim, iletişim, uyarlanabilir davranışı pekiştirme ve işbirliğine dayalı problem çözme, aile terapisinin merkezinde yer almalıdır (Nichols, 2013).

Kişilerarası Psikoterapi: Kişilerarası psikoterapi (KIPT), kişilerarası sorunların bir alanına odaklanan kısa vadeli, oldukça yapılandırılmış bir psikoterapi türüdür. İlişkilerin hem sayısı hem de kalitesi açısından önemli bir sorunun olduğu durumlarda kullanılmaktadır. Genellikle on iki ila on altı hafta sürer. KİPT'de hasta ve terapist genellikle mevcut ilişkilere ve terapistle olan ilişkiye odaklanır. Birlikte, ilişkilerdeki yaygın uyumsuz kalıpları belirlemeye ve bunları alternatif uyumlu kalıplarla değiştirmeye çalışlır (Levenson ve Frank, 2014).

Destekleyici Psikoterapi: Destekleyici psikoterapi, terapötik ilişkiyi, çevresel müdahaleleri, eğitimi, tavsiyeleri ve önerileri, cesaretlendirmeyi ve övgüyü, sınır belirleme ve yasakları ve uyumsuz savunmaları zayıflatırken, hastanın uyarlanabilir savunmalarını, güçlü yanlarını ve yeteneklerini geliştirir. Destekleyici psikoterapide hastaların terapistlerine güven duydukça, bu deneyimi yaşamlarındaki önemli diğer kişilere genellemeyi öğreneceklerine inanılır. Amaç, hastaya ihtiyaçlarını karşılamanın ve sağlıklı biçimde kendini savunmanın alternatif yollarının öğretilmesi ve bu yolla hastanın "manipülatif" davranışlarının azaltılması, ihtiyaçlarının karşılanması için sağlıklı bir kendini savunmayı öğrenmeleridir (Winston ve ark., 2004).

\section{Sonuç ve Öneriler}

Bu çalışmada, ergenlerde BKB tanısının önemi kuramsal alanyazın değerlendirilerek tartışılmıştır. Kişilik, ergenlik yıllarında hala yapım aşa- 
masındadır ve zihinsel bozuklukların tanısal ve istatistiksel el kitabında (DSM-V), BKB tanısı (ya da başka herhangi bir kişilik bozukluğunun tanısı) 18 yaşın üzerindeki hastalarla sınırlandırılmıştır. Bununla birlikte, çok sayıda klinisyen, BKB'nin genellikle ergenlik döneminde başladığını düşünmekte terapötik bir bakış açısıyla, BKB teşhisi ergenlerde de yapılabileceğine inanılmaktadır. Ergenler için olası tedavi seçenekleri genç yetişkinlerle hemen hemen aynıdır ve erken tanılama ergenin spesifik tedaviye başlamasına imkan tanıyacaktır (Paris, 2004; Chanen ve ark., 2020). Bu nedenle, BKB'nin genç bireylerde tespit edilip müdahale edilmesi, bu örüntünün kemikleşmiş bir yapı haline dönüşmeden çözümlenmesine imkan tanıyacaktır. Bu doğrultuda tanılamanın öneminin, ergenin kişilik örüntüsünün içinde barındırdığı niteliklerinin (özellikle durumsal değil, yaygınlık gösteren ve durağanlık sergileme eğiliminde olan niteliklerin), halihazırda sergilenen sonuçları ile olası doğurgularının belirlenmeside ve ihtiyaç görülmesi halinde, semptom kümesine karşı etkinliği bilinen bir psikoterapi modelinin seçilmesinde kolaylaştırıcı rolü ile tedaviyi hızlandırıcı rolünden geldiği düşünülmektedir. 


\title{
EXTENDED ABSTRACT
}

\section{Evaluation of Determining Borderline Personality Disorder in Adolescence}

\author{
* \\ Haydeh Faraji \\ İstanbul Aydin University
}

Borderline Personality Disorder; is a disorder dominated by a common and chronic imbalance in the individual's sense of identity, relationships, affect, behaviors and cognitive patterns. It can lead to complex psychosocial problems, including dysfunction in professional and social relationships legal and financial problems (Tomko et al., 2014).

Despite the longstanding general acceptance that the origins of personality disorders are in childhood and adolescence, diagnosing BPD before the age of 18 is controversial (Chanen ve McCutcheon, 2008). In many parts of the world, clinicians are still hesitant to diagnose BPD in young people, mainly due to four concerns: First, the diagnosis of BPD in adolescence is not valid. Second, typical features of BPD such as emotional instability or disturbing self-image are normative among adolescents. Third, personality development is still changing and this prevents diagnosis. Fourth, and probably most importantly, clinicians want to protect their patients from the stigmatizing and pessimistic attitudes that the diagnosis of BPD will bring (Chanen et al., 2008).

The arguments against the use of BPD diagnosis in adolescents are based on the dynamic and evolving nature of the adolescent personality. As adolescents constantly learn and develop as a result of interpersonal exposure, reflection, and ongoing neurocognitive changes, adolescent personality is dynamic in nature, and this dynamism is seen as a feature that excludes the diagnosis of a structured personality disorder. However, when evaluated from another perspective, this dynamic structure offers an important advantage in resolving the formations that do not go well in the personality pattern that is just being formed and developing.

The public cost of BPD is significantly higher because patients use more treatment than those with other psychiatric disorders, obtain less educational qualifications, and experience higher unemployment prob- 
lems (Ansel et al., 2007; Sasone ve Sasone, 2012). At the same time, when the histories of people diagnosed with BPD are examined, it is seen that the rate of hospitalization before the diagnosis is quite high (Guile ve Greenfield, 2004). Severe borderline personality traits can negatively affect the adolescent's ability to reach important developmental milestones as they move into early adulthood (Winograd et al., 2008). Taken together, these observations strongly indicate that early diagnosis and intervention are important to prevent the establishment of psychopathology over time (Beauchaine et al., 2008).

Considering BPD as dimensions of personality "pattern" without considering it as a structural and fixed model, and diagnosing situations at the level of boderline personality disorder in adolescents by evaluating these dimensions through the level of rigidity and adaptation to different situations and conditions, it is quite it will prevent it from becoming a difficult structure (Greenfield et al., 2015). This dimensional approach includes emotional, behavioral, cognitive, interpersonal disorder and self disorder dimensions of borderline personality disorder.

Emotional Variability: Affect in borderline personality disorder is negative, intense, and changeable. Affective fluctuations are frequently encountered in borderline patients, who are almost always in a crisis situation. Anger appears to be the key factor of affective volatility, and is sometimes seen with the devaluation or projection of devaluation of meaningful others, particularly early objects. In borderline personality disorder, affect typically shows fluctuations and transitions between negative emotions such as anger, irritability, anxiety, depression, and dysphoria (Faraji, 2020).

Behavioral Variability: Borderline patients often have difficulties in controlling their emotions. In the same direction, talk about their bodies getting out of control is frequently encountered. Impulsivity, especially aggressive impulsivity, is accepted as one of the leading components of borderline personality disorder due to the nature of borderline patients as well as the influence of their upbringing conditions. . Risk-taking behaviors and self-harming behaviors are frequently occurring in the context of behavioral variability during adolescence (Kaess et al., 2014a, b). 
The term "deliberate self-harm" (DSHV) is defined as the act of deliberate direct destruction of one's own body tissue, which includes a series of different self-harming behaviors with or without suicidal intention (Brunner et al., 2014). Risk-taking behaviors are defined as behaviors that can affect adolescents' physical well-being and psychosocial functioning, and include a wide variety of behaviors, including substance use, excessive media use, and confusion (Leather, 2009).

Cognitive Variability: Cognitive impairments are particularly pronounced in unstructured or stressful situations, as borderline patients have difficulty maintaining a relationship with reality. These temporary cognitive impairments; It includes dissociation, paranoia, and other semi-psychotic experiences in situational. The 'stressor' in this situation is typically a loss of contact with an important object for which the loss is felt to be inevitable and irreversible (Faraji, 2020).

Interpersonal Variability: This group of patients, who feel both commitment and hostility at the same time, have irregular interpersonal relationship patterns. The fact that imbalance in interpersonal relationships is frequently encountered and the imbalance is quite common in the daily life of borderline patients has made this feature a basic feature in the diagnosis of borderline personality disorder. It is observed that they have a very low tolerance to loneliness, they try to socialize in a compulsive manner, and they often complain of boredom and feelings of inner emptiness (Faraji, 2020).

Self-Variability: Difficulty maintaining a stable sense of self is a common feature of borderline personality disorder. The "boundary" that separates our existence from the present moment does not exist or is ambiguous for these people. Borderline patients' being limited to the 'present moment' fuel their emotional instability and relational inconsistencies. It is difficult for the borderline patient to distance themselves from their experiences; the individual is unable to establish a satisfactory distance between himself and his experiences. The borderline patient has a tendency to identify processes with the moment he experiences, he is completely immersed in the present moment. For these people, the individu- 
al is limited to whatever he experiences in the here and now. There is no boundary that separates the present from the self, the two are pervaded and interwined(Englebert, 2017).

There is a growing body of evidence to support both the diagnosis and treatment of BPD in adolescence. BPD has been found to be reliable and valid in adolescence as well as in adulthood (Chanen et al., 2008; Miller et al., 2008). BPD shows a similar stability during adolescence compared to adulthood (Chanen et al., 2004). Although there is no difference in treatments for young and adult forms of the disorder, it is stated that early intervention is important in terms of the course and severity of the disease in the treatment of the disorder (Chanen et al., 2013).

Cognitive behavioral therapy, schema therapy, system training for emotional predictability and problem solving, mentalization-based therapy, transference-focused therapy, cognitive analytical therapy, family therapy, interpersonal psychotherapy, supportive psychotherapy are the main psychotherapy methods used in both adolescent and adult borderline personality disorder psychotherapy.

\section{Kaynakça / References}

Aguirre, B. (2014). Borderline personality disorder in adolescence. Beverly: Fair Winds Press.

American Psychiatric Association. (2013). Diagnostic and statistical manual of mental disorders (DSM-5®).

Ansell, E. B., Sanislow, C. A., McGlashan, T. H. ve Grilo, C. M. (2007). Psychosocial impairment and treatment utilization by patients with borderline personality disorder, other personality disorders, mood and anxiety disorders, and a healthy comparison group. Comprehensive Psychiatry, 48(4), 329-336.

Atak, İ.E. (2012). Sınır işleyiş kavramının sınırları: Rorschach Testi ile değerlendirme. Yansitma Psikopatoloji ve Projektif Testler Dergisi, 18(1), 4755.

Bateman, A. ve Fonagy, P. (1999). Effectiveness of partial hospitalization in the treatment of borderline personality disorder: A randomized controlled trial. American journal of Psychiatry, 156(10), 1563-1569. 
Bateman, A. ve Fonagy, P. (2013). Mentalization-based treatment. Psychoanalytic inquiry, 33(6), 595-613.

Beauchaine, T. P., Neuhaus, E., Brenner, S. L. ve Gatzke-Kopp, L. (2008). Ten good reasons to consider biological processes in prevention and intervention research. Development and psychopathology, 20(3), 745-774.

Biskin, R. S., Paris, J., Renaud, J., Raz, A. ve Zelkowitz, P. (2011). Outcomes in women diagnosed with borderline personality disorder in adolescence. Journal of the Canadian Academy of Child and Adolescent Psychiatry, 20(3), 168-174.

Blum, N., St. John, D., Pfohl, B., Stuart, S., McCormick, B., Allen, J. ve Black, D. W. (2008). Systems Training for Emotional Predictability and Problem Solving (STEPPS) for outpatients with borderline personality disorder: a randomized controlled trial and 1-year followup. American Journal of Psychiatry, 165(4), 468-478.

Bondurant, H., Greenfield, B. ve Tse, S. M. (2004). Construct validity of the adolescent borderline personality disorder: A review. The Canadian child and adolescent psychiatry review, 13(3), 53-57.

Brodsky, B.S., Malone, K.M., Ellis, S.P., Dulit, R.A. ve Mann, J.J. (1997). Characteristics of borderline personality disorder associated with suicidal behavior. American Journal of Psychiatry, 154(12), 1715-1719.

Brunner, R., Kaess, M., Parzer, P., Fischer, G., Carli, V., Hoven, C. W. ve Wasserman, D. (2014). Life-time prevalence and psychosocial correlates of adolescent direct self-injurious behavior: A comparative study of findings in 11 European countries. Journal of Child Psychology and Psychiatry, 55(4), 337-348.

Carli, V., Hoven, C.W., Wasserman, C., Chiesa, F., Guffanti, G., Sarchiapone, M., et al (2014). A newly identified group of adolescents at "invisib$\mathrm{le}^{\prime \prime}$ risk for psychopathology and suicidal behavior: Findings from the SEYLE study. World Psychiatry, 13(1), 78-86.

Cerutti, R., Manca, M., Presaghi, F. ve Gratz, K.L. (2011). Prevalence and clinical correlates of deliberate self-harm among a community sample of Italian adolescents. J. Adolesc., 34(2), 337-347.

Chabrol, H., Montovany, A., Chouicha, K., Callahan, S. ve Mullet, E. (2001). Frequency of borderline personality disorder in a sample of French high school students. The Canadian Journal of Psychiatry, 46(9), 847849. 
Chanen, A. M., Jovev, M., McCutcheon, L.K., Jackson, H.J. ve McGorry, P.D. (2008). Borderline personality disorder in young people and the prospects for prevention and early intervention. Current Psychiatry Reviews, 4(1), 48-57.

Chanen, A.M. ve Kaess, M. (2012). Developmental pathways to borderline personality disorder. Current psychiatry reports, 14(1), 45-53.

Chanen, A.M. ve McCutcheon, L. (2013). Prevention and early intervention for borderline personality disorder: Current status and recent evidence. The British Journal of Psychiatry, 202(54), 24-29.

Chanen, A.M., Jackson, H.J., McGorry, P. D., Allot, K.A., Clarkson, V. ve Yuen, H. P. (2004). Two-year stability of personality disorder in older adolescent outpatients. Journal of personality disorders, 18(6), 526541.

Chanen, A.M., Jovev, M. ve Jackson, H.J. (2007). Adaptive functioning and psychiatric symptoms in adolescents with borderline personality disorder. Journal of Clinical Psychiatry, 68(2), 297-306.

Chanen, A.M. ve McCutcheon, L.K. (2008). Personality disorder in adolescence: The diagnosis that dare not speak its name. Pers Ment Health. 2(1), 35-41

Chanen, A.M., Nicol, K., Betts, J.K. ve Thompson, K.N. (2020). Diagnosis and treatment of borderline personality disorder in young people. Curr. Psychiatry Rep., 22(25), 1-8.

Deschamps, P. K. ve Vreugdenhil, C. (2008). Stability of borderline personality disorder from childhood to adulthood: A literature review. Tijdschrift voor Psychiatrie, 50(1), 33-41.

Englebert, J. (2017). Ubiquité et situation: Pour une considération topologique de la limite. Le Cercle Herméneutique, 28, 107-113.

Evren, C., Cinar, O., Evren, B. ve Celik, S. (2012). Relationship of selfmutilative behaviours with severity of borderline personality, childhood trauma and impulsivity in male substance-dependent inpatients. Psychiatry Research, 200(1), 20-25.

Faraji, H ve Tezcan, A.E. (2021). Ergen. Ankara: Eğiten Kitap.

Faraji, H. (2020). Borderline kişilik bozuklukluğunda duygu düzenleme güçlüğü ve ruhsal işleyişin rorschach testindeki görünümü. Doğuş Üniversitesi Lisansüstü Enstitüsü, İstanbul. 
Fein, G., Price, M. ve Cardenas, V.A. (2018). Borderline personality disorder symptoms in treatment-naive actively drinking alcoholics. Alcohol, 68(3), 81-89.

Freud, A. (1958). Adolescence. Psychoanalytic Study of the Child, 13, 255-278.

Goodman, M., New, A. S., Triebwasser, J., Collins, K. A. ve Siever, L. (2010). Phenotype, endophenotype, and genotype comparisons between borderline personality disorder and major depressive disorder. Journal of personality disorders, 24(1), 38-59.

Greenfield, B., Henry, M., Lis, E., Slatkoff, J., Guilé, J.-M., Dougherty, G., Zhang, X., Raz, A., Eugene Arnold, L., Daniel, L., et al., (2015). Correlates, stability and predictors of borderline personality disorder among previously suicidal youth. Eur. Child Adolesc. Psychiatry, 24(4), 397-406.

Groschwitz, R.C., Plener, P.L., Kaess, M., Schumacher, T., Stoehr, R. ve Boege, I. (2015). The situation of former adolescent self-injurers as young adults: a follow-up study. BMC Psychiatry,15(1), 1-9.

Guilé, J.M., Boissel, L., Alaux-Cantin, S. ve de La Rivière, S.G. (2018). Borderline personality disorder in adolescents: prevalence, diagnosis, and treatment strategies. Adolesc. Health Med. Ther., 9, 199-210.

Guile, J.M. ve Greenfield, B.G. (2004). Introduction personality disorders in childhood and adolescence. Can Child Adolesc Psychiatry Rev,13(3), 51-2.

Gunderson, J. G., Bender, D., Sanislow, C., Yen, S., Rettew, J. B., DolanSewell, R. ve Skodol, A.E. (2003). Plausibility and possible determinants of sudden "remissions" in borderline patients. Psychiatry: Interpersonal and Biological Processes, 66(2), 111-119.

Johnson, J.G., Cohen, P., Kasen, S., Skodol, A.E. ve Oldham, J.M. (2008). Cumulative prevalence of personality disorders between adolescence and adulthood. Acta Psychiatr Scand., 118(5), 410-413.

Kaess, M., Brunner, R. ve Chanen, A. (2014). Borderline personality disorder in adolescence. Pediatrics, 134(4), 782-793.

Kaess, M., Brunner, R., Parzer, P., Carli, V., Apter, A., Balazs, J.A., et al., (2014)b. Riskbehaviour screening for identifying adolescents with mental health problems in Europe. Eur. Child Adolesc. Psychiatry, 23(7), 611-620.

Kaess, M., von Ceumern-Lindenstjerna, I.A., Parzer, P., Chanen, A., Mundt, C., Resch, F. ve Brunner, R. (2013)a. Axis I and II comorbidity and 
psychosocial functioning in female adolescents with borderline personality disorder. Psychopathology, 46(1), 55-62.

Kahraman, H. (2018). Klinik bir olgu olarak yalnızlık: Yalnızlık ve psikolojik bozukluklar. AYNA Klinik Psikoloji Dergisi, 5(2) 1-24.

Kernberg, P. F. ve Shapiro, T. (1990). Resolved: Borderline personality exists in children under twelve. Journal of the American Academy of Child and Adolescent Psychiatry, 29(3), 478-483.

King, R.A., Schwab-Stone, M., Flisher, A.J., Greenwald, S., Kramer, R.A., Goodman, S.H.,et al., 2001. Psychosocial and risk behavior correlates of youth suicide attempts and suicidal ideation. Journal of the American Academy of Child and Adolescent Psychiatry, 40(7), 837-846.

Leather, N.C. (2009). Risk-taking behaviour in adolescence: A literature review. Journal of Child Health Care, 13(3), 295-304.

Leichsenring, F., Leibing, E., Kruse, J., New, A. S. ve Leweke, F. (2011). Borderline personality disorder. The Lancet, 377(9759), 74-84.

Lenzenweger, M.F. (2008). Epidemiology of personality disorders. Psychiatric Clinics of North America, 31(3), 395-403.

Levenson, J.C., Frank, E. (2014). Kişilerarası psikoterapi (G. Akkaya, Çeviri Ed.). İstanbul: Okyanus Yayınları.

Lieb, K., Zanarini, M.C., Schmahl, C., Linehan, M.M. ve Bohus, M. (2004). Borderline personality disorder. The Lancet, 364(9432), 453-461.

Miller, A.L., Muehlenkamp, J.J. ve Jacobson, C.M. (2008). Fact or fiction: Diagnosing borderline personality disorder in adolescents. Clinical psychology review, 28(6), 969-981.

Miller, A.L., Neft, D. ve Golombeck, N. (2008) Borderline personality disorder and adolescence. Social Work in Mental Health, 6(1-2), 85-98.

Monte, F. L. ve Englebert, J. (2018). Borderline personality disorder and lived time. L'Évolution Psychiatrique, 83(4), 37-45.

Monti, M.R. ve D'Agostino, A. (2016). Abnormal bodily experience in borderline personality disorder: Clinical issues and psychopathological perspectives. Clin Neuropsychiatry, 13(3), 37-42.

Moran, P., Coffey, C., Romaniuk, H., Degenhardt, L., Borschmann, R. ve Patton, G.C. (2015). Substance use in adulthood following adolescent self-harm: A population-based cohort study. Acta Psychiatr. Scand., 131(1), 61-68.

Moran, P., Coffey, C., Romaniuk, H., Olsson, C., Borschmann, R., Carlin, J.B. ve Patton, G.C. (2012). The natural history of self-harm from adoles- 
cence to young adulthood: a population-based cohort study. Lancet, 379(9812), 236-243.

New, A.S. ve Siever, S.L. (2002). Neurobiology and genetics of borderline personality disorder. Psychiatric Annals, 32(6), 329-336.

Nichols, N.P. (2013). Aile terapisi kavramlar ve yöntemler (O. Gündüz, Çeviri Ed.).İstanbul: Kaknüs Yayınları.

Paris, J. (2002). Chronic suicidality among patients with borderline personality disorder. Psychiatric services, 53(6), 738-742.

Paris, J., (2004). Personality disorders over time: Implications for psychotherapy. Am. J. Psychother, 58(4), 420-429.

Rafaeli, E., Young, J.E. ve Bernstein, D.P. (2013). Şema terapi. İstanbul: Psikonet Yayınları.

Ryle, A. ve Low, J. (1993). Cognitive analytic therapy. In Comprehensive handbook of psychotherapy integration. Boston, MA: Springer.

Sansone, R.A., Gaither, G.A. ve Songer, D.A. (2002). The relationships among childhood abuse, borderline personality, and self-harm behavior in psychiatric inpatients. Violenceand Victims, 17(1), 49.

Tomko, R. L., Trull, T. J., Wood, P. K. ve Sher, K. J. (2014). Characteristics of borderline personality disorder in a community sample: Comorbidity, treatment utilization, and general functioning. Journal of personality disorders, 28(5), 734-750.

Tomko, R.L., Trull, T.J., Wood, PK. ve Sher, K.J. (2014). Characteristics of borderline personality disorder in a community sample: Comorbidity, treatment utilization, and generals functioning. Journal of Personality Disorders, 28, 734-750.

Türkçapar, H. (2018). Bilişsel davranışçı terapi- temel ilkeler ve uygulama. İstanbul: Epsilon Yayınevi.

Tyrer, P., Crawford, M., Mulder, R. ve The ICD-11 Working Group for the Revision of Classification of Personality Disorders. (2011). Reclassifying personality disorders. The Lancet, 377(9780), 1814-1815.

Vega, D., Torrubia, R., Soto, À., Ribas, J., Soler, J., Pascual, J.C., et al. (2017). Exploring the relationship between non suicidal self-injury and borderline personality traits in young adults. Psychiatry Res., 256, 403411.

Welch, S. S. ve Linehan, M. M. (2002). High-risk situations associated with parasuicide and drug use in borderline personality disorder. Journal of personality disorders, 16(6), 561-569. 
White, C. N., Gunderson, J. G., Zanarini, M. C. ve Hudson, J. I. (2003). Family studies of borderline personality disorder: A review. Harvard Review of Psychiatry, 11(1), 8-19.

Winograd, G., Cohen, P. ve Chen, H. (2008). Adolescent borderline symptoms in the community: prognosis for functioning over 20 years. Journal of Child Psychology and Psychiatry, 49(9), 933-941.

Winston A., Rosenthal R.N., Pinsker H. (2004). Amaçlar ve etki şekli. Güleç G. (Ed.), içinde Destekleyici Psikoterapiye Giriş. (13-25). Ankara: Tuna Matbaacilik.

Zanarini, M. C., Frankenburg, F. R., Hennen, J. ve Silk, K. R. (2003). The longitudinal course of borderline psychopathology: 6-year prospective follow-up of the phenomenology of borderline personality disorder. American Journal of Psychiatry, 160(2), 274-283.

Zanarini, M. C., Frankenburg, F. R., Hennen, J., Reich, D. B. ve Silk, K. R. (2005). Psychosocial functioning of borderline patients and axis II comparison subjects followed prospectively for six years. Journal of Personality Disorders, 19(1), 19-29.

Zanarini, M. C., Frankenburg, F. R., Hennen, J., Reich, D. B. ve Silk, K. R. (2006). Prediction of the 10-year course of borderline personality disorder. American Journal of Psychiatry, 163(5), 827-832.

Zanarini, M.C., Frankenburg, F.R., Reich, D.B., Silk, K. R., Hudson, J. I. ve McSweeney, L.B. (2007). The subsyndromal phenomenology of borderline personality disorder: A 10-year follow-up study. American Journal of Psychiatry, 164(6), 929-935.

Zimmermann, M. ve Mattia, J. I. (1999). Axis I diagnostic comorbidity and borderline personality disorder. Comprehensive Psychiatry, 40(4), 245252.

Zittel, Conklin, C. ve Westen, D. (2005). Borderline personality disorder in clinical practice. American Journal of Psychiatry, 162(5), 867-875.

\section{Kaynakça Bilgisi / Citation Information}

Faraji, H. (2021). Borderline kişilik bozukluğunun ergenlik döneminde belirlenmesine dair bir değerlendirme. OPUS-Uluslararası Toplum Araştırmaları Dergisi, 18(43), 7139-7166. DOI: 10.26466/opus. 898571. 